\title{
Influence of piston surface treatment on piston assembly friction in an eco-mileage vehicle engine
}

ARTICLE INFO

Received: 9 August 2021

Revised: 22 September 2021

Accepted: 23 September 2021

Available online: 3 October 2021
This study investigated the effect on piston assembly friction after treating piston surfaces with a fine particle bombarding process, using a friction measurement apparatus with a floating cylinder liner, similar to an eco-mileage vehicle engine. Friction was measured in four conditions: (1) no treatment (standard piston in a commercially-available engine), (2) micro dimple treatment (45 um ceramic particles were air-blasted onto the piston surface), (3) molybdenum disulfide $\left(\mathrm{MoS}_{2}\right)$ shot treatment (1 $\mu \mathrm{m} \mathrm{MoS} \mathrm{S}_{2}$ particles were air-blasted onto the piston surface), and (4) combination of the previous two micro dimple and MoS $\mathrm{S}_{2}$ shot treatments (first $45 \mu \mathrm{m}$ ceramic particles and then $1 \mu \mathrm{m} \mathrm{MoS} \mathrm{S}_{2}$ were air-blasted onto the piston surface). Results indicated that friction decreased in the following order: no treatment > micro dimple treatment $>\mathrm{MoS}_{2}$ shot treatment $>$ combination of micro dimple and $\mathrm{MoS}_{2}$ shot treatments.

Key words: eco-mileage vehicle engine, floating cylinder liner, fine particle bombarding, piston, piston assembly friction

This is an open access article under the CC BY license (http://creativecommons.org/licenses/BY/4.0/)

\section{Introduction}

In eco-mileage vehicles, reducing engine friction is an effective means for improving fuel efficiency. Because the piston assembly friction (the friction between the piston, the piston rings, and the cylinder liner) makes a significant contribution to engine friction $[1,3,4,6]$, it is important to reduce this piston assembly friction. The friction between the piston and the cylinder liner accounts for more than $50 \%$ of the piston assembly friction, and its ratio increases with increasing engine speed and decreasing engine load [7]. There have been reports on reducing piston assembly friction by applying a surface treatment on the piston skirt $[2,5,9-11,13-15]$. One approach plates a piston with tin [5]. Tin not only reduces friction, but also simplifies the break-in run. However this tin plating wears out during protracted engine operation, losing the friction reduction effect. Another approach plates a piston with a resin coating in which molybdenum disulfide $\left(\mathrm{MoS}_{2}\right)$ and polytetrafluoroethylene (PTFE) are dispersed in a resin binder [2, 5, 15], a resin coating in which fine hard particles are dispersed in a resin binder [14], or a resin coating of two layers in which $\mathrm{MoS}_{2}$ is dispersed in a resin binder in the upper layer and graphite is dispersed in the lower layers [13]. This rein does not wear out even during protracted engine operation, achieving sustainable friction reduction. But the performance of slide and transfer of solid lubricants such as $\mathrm{MoS}_{2}$ and PTFE, is suppressed by the resin binder [10]. In addition, the thickness of these resin coatings is approximately $10 \mu \mathrm{m}$, so it is necessary to design the piston with advance consideration of the final coating thickness. Yet another approach uses a micro dimple treatment (by air-blasting fine ceramic particles at a high speed) $[9,11]$ and a $\mathrm{MoS}_{2}$ shot treatment (by air-blasting fine $\mathrm{MoS}_{2}$ particles at a high speed) $[10,11]$ on the piston surface using a fine particle bombarding (FPB) process. This approach reduces friction even during protracted engine operation, and has minimal effect on piston dimension. This process (of micro dimple and $\mathrm{MoS}_{2}$ shot treatments with FPB) can be easily applied to the piston in an eco-mileage vehicle engine, where it can be expected to reduce friction even during protracted operation. Our previous study developed a friction measurement apparatus with a floating cylinder liner, by using components of an eco-mileage vehicle engine as much as possible [8]. This study employs that measurement apparatus to quantify the effect on piston assembly friction of piston surface treated with a FPB process.

\section{Experimental apparatus and method}

Figure 1 shows the apparatus to measure piston assembly friction with the floating liner, as developed in our previous study [8]. This measurement apparatus was designed to be similar as possible to an actual eco-mileage vehicle engine. So it employed a commercially-available, four-stroke, air-cooled, horizontal, single-cylinder, gasoline engine, displacing $49 \mathrm{~mL}$, with a bore diameter of $39 \mathrm{~mm}$ and a stroke of $41.4 \mathrm{~mm}$. The crankcase of this engine was cut, and a cover was attached to the cut of the crankcase. The engine was turned from horizontal to vertical. The floating liner was produced by machining the outer periphery of the air-cooled cylinder (aluminum finned cylinder casting cast-iron liner). This floating liner was installed in the aluminum cylinder block. Joint plates were installed in the grooves on the outer periphery of the floating liner at both the thrust and the anti-thrust sides. Then the joint plates, as well as load washers of piezo type, were mounted in the cylinder block, as shown in Fig. 2. To suppress lateral displacement due to piston thrust force, clamping bolts were mounted to the cylinder block at four sides: thrust, anti-thrust, front, and rear. Heaters were installed in the cylinder block at the thrust, anti-thrust, and rear sides, and thermocouples were installed into the clamping bolts at the front and rear sides so that the bore surface temperature of the floating liner could be measured and adjusted. In addition, an oil tank was set outside the engine, and a heater and a thermocouple were installed into the oil tank to adjust the oil temperature to a fixed temperature. The heated oil was 
then pumped from the oil tank to a pipe in the upside of the crankcase, and supplied from there to the crankshaft at a flow rate of $600 \mathrm{~mL} / \mathrm{min}$.

Figure 3 shows the four experimental pistons and the surface shapes on the piston skirts. The piston without surface treatment (1) is standard part of a commerciallyavailable engine, and has a streaked sliding surface (Ra 2.4 $\mu \mathrm{m})$ and three grooves in the skirt. In the micro dimple treatment (2) ceramic particles with a diameter of $45 \mu \mathrm{m}$ were air-blasted on the standard piston surface. In the $\mathrm{MoS}_{2}$ shot treatment (3) $\mathrm{MoS}_{2}$ particles with a diameter of $1 \mu \mathrm{m}$ were air-blasted on the standard piston surface. In the combination of micro dimple and $\mathrm{MoS}_{2}$ shot treatments (4) first ceramic particles with a diameter of $45 \mu \mathrm{m}$ were air-blasted on the standard piston surface, and then $\mathrm{MoS}_{2}$ particles with a diameter of $1 \mu \mathrm{m}$ were air-blasted onto it. There was no difference in the outer diameter, measured with a micrometer, at each position of the pistons with and without surface treatments.

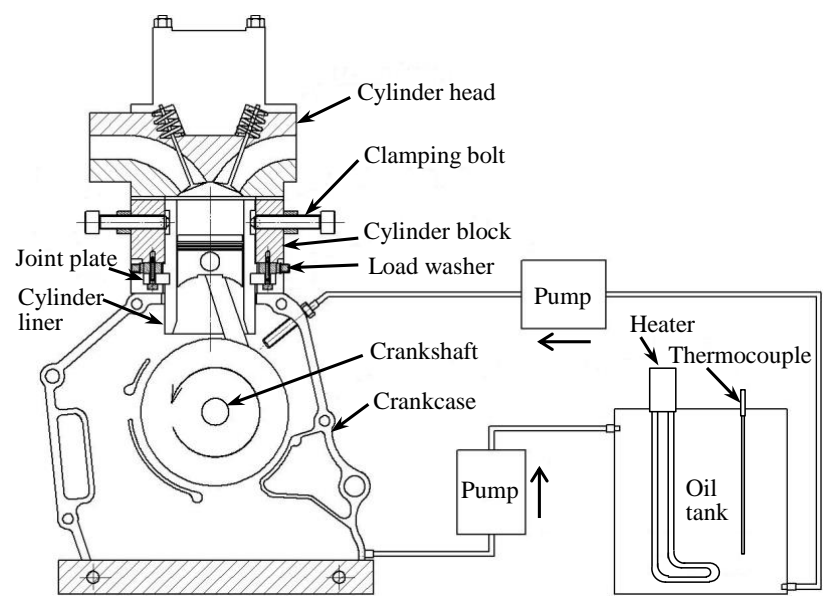

Fig. 1. Measurement apparatus of piston assembly friction

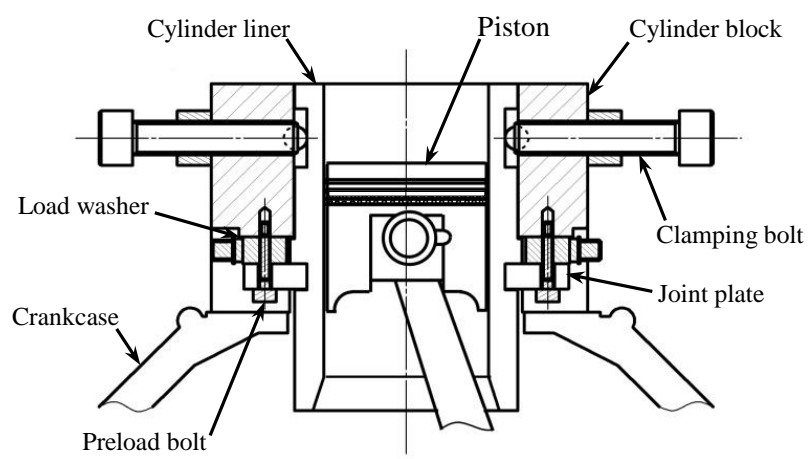

Fig. 2. Measurement unit of piston assembly friction with floating liner

Table 1 shows the experimental rings, which are standard parts of a commercially-available engine. These rings had been fully run earlier [8].

The floating liner had been also fully operated earlier [8]. The roughness of the sliding surface on the liner bore was $\mathrm{Rz}_{\mathrm{JIS}} 1.22 \sim 1.34 \mu \mathrm{m}$ (Ra $\left.0.20 \sim 0.22 \mu \mathrm{m}\right)$.

In the experiment, the intake and exhaust valves were not activated (no cylinder pressure was applied) while the engine was operated by motoring. Using the same rings and floating liner, each experimental piston was installed in the engine. Before measuring piston assembly friction, the engine was run in for 20 hours, at an engine speed of 1600 $\mathrm{rpm}$, with temperatures of the liner bore and lubricant of $80^{\circ} \mathrm{C}$. Then the piston assembly friction was measured at temperatures of $40^{\circ} \mathrm{C}, 60^{\circ} \mathrm{C}$ and $80^{\circ} \mathrm{C}$, and at engine speeds from $800 \mathrm{rpm}$ to $1600 \mathrm{rpm}$ every $200 \mathrm{rpm}$. Table 2 shows the kinematic viscosities of the experimental lubricant (Honda genuine Ultra Green) at each temperature, measured with the Redwood viscometer.

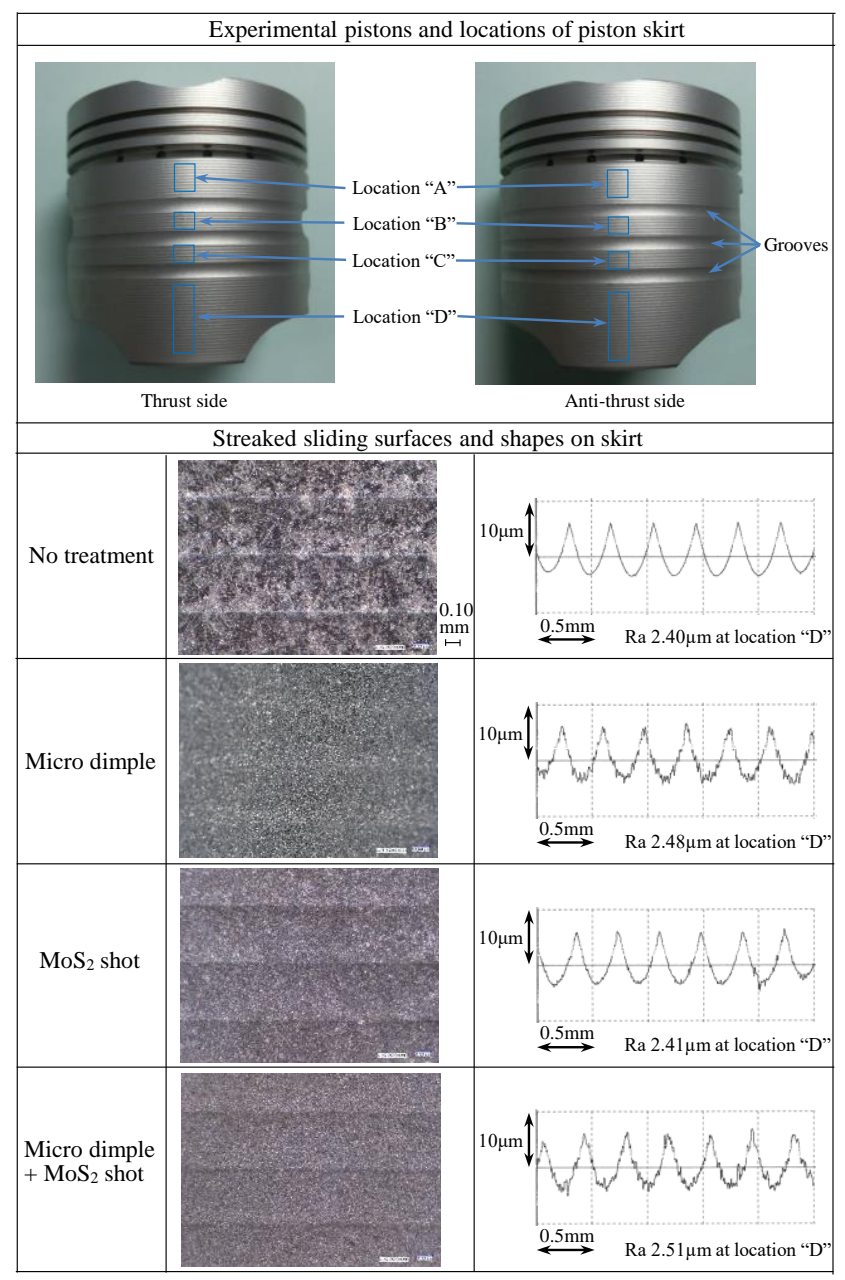

Fig. 3. Experimental pistons and the surface shapes on the piston skirts

Table 1. Experimental piston rings

\begin{tabular}{|l|l|l|}
\hline \multicolumn{1}{|c|}{ Top ring } & \multicolumn{1}{|c|}{ Second ring } & Oil ring \\
\hline & & \\
\hline
\end{tabular}

Table 2. Kinematic viscosities of experimental lubricant

\begin{tabular}{|c|c|}
\hline Temperature & Kinematic viscosity \\
\hline $40^{\circ} \mathrm{C}$ & $30.3 \mathrm{~mm}^{2} / \mathrm{s}$ \\
\hline $60^{\circ} \mathrm{C}$ & $15.8 \mathrm{~mm}^{2} / \mathrm{s}$ \\
\hline $80^{\circ} \mathrm{C}$ & $10.4 \mathrm{~mm}^{2} / \mathrm{s}$ \\
\hline
\end{tabular}




\section{Results and discussion}

Figures 4 to 6 show the measurement results of the piston assembly friction at an engine speed of $1000 \mathrm{rpm}$ and at temperatures of $40^{\circ} \mathrm{C}, 60^{\circ} \mathrm{C}$ and $80^{\circ} \mathrm{C}$, respectively. In Figs 4 to 6 , crank angles of $0^{\circ}$ and $360^{\circ}$ represent engine top dead center (TDC), and $180^{\circ}$ bottom dead center (BDC). Since the intake and exhaust valves were not activated, only two strokes of the piston (downward stroke and upward stroke) are indicated. At each temperature, not only near TDC and BDC but also near the center of the stroke, friction decreased in the following order: no treatment $>$ micro dimple treatment $>\mathrm{MoS}_{2}$ shot treatment $>$ combination of micro dimple and $\mathrm{MoS}_{2}$ shot treatments. As the temperature increased, the friction reduction ratio of each surface treatment (compared to no treatment) decreased, especially near TDC and BDC.

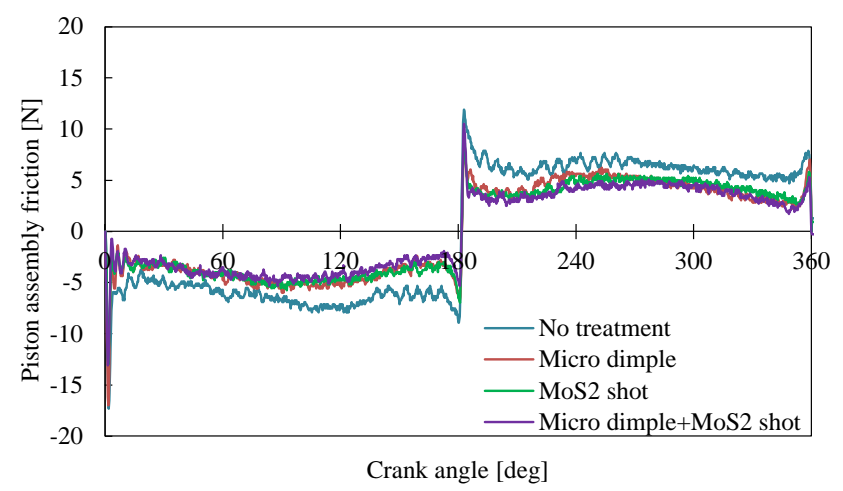

Fig. 4. Piston assembly friction at $40^{\circ} \mathrm{C}(1000 \mathrm{rpm})$

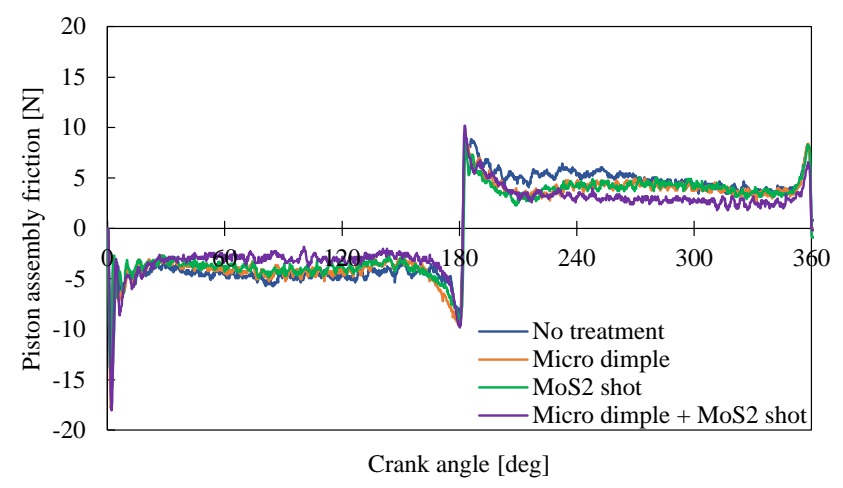

Fig. 5. Piston assembly friction at $60^{\circ} \mathrm{C}(1000 \mathrm{rpm})$

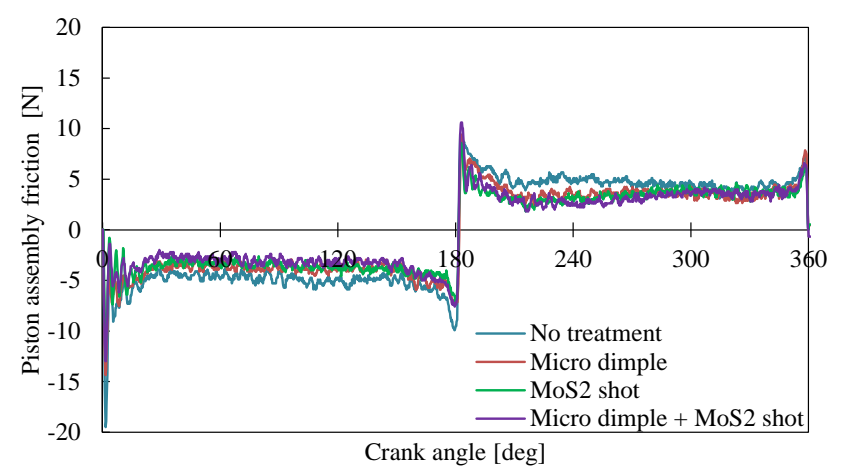

Fig. 6. Piston assembly friction at $80^{\circ} \mathrm{C}(1000 \mathrm{rpm})$
Figures 7 to 10 show the Stribeck diagrams (at 1000 rpm with crank angles of $3^{\circ}$ to $177^{\circ}$ and $183^{\circ}$ to $357^{\circ}$ ) for each piston corresponding to the friction measurement results in Figs 4 to 6. Here the friction coefficient was obtained by dividing the absolute value of friction by the sum of the thrust force of the piston (which was obtained by multiplying the inertial force of the piston by the tangent of the tilt angle of the connecting rod) and the normal force of the rings (which was obtained by multiplying the ring surface pressures by the outer peripheral surface areas of the rings). The lubrication parameter was also obtained by multiplying the lubricant viscosity, $\mu$, by the piston speed, $\mathrm{U}$, and dividing by $\mathrm{W}$, the sum of the surface pressures of the piston skirt (one skirt side) and the rings. In Figs 7 to 10 , fluid lubrication was dominant at lower temperatures, but mixed lubrication was dominant at higher temperatures. In all lubrication regions, friction coefficient again tended to decrease in the following order: no treatment $>$ micro dimple treatment $>\mathrm{MoS}_{2}$ shot treatment $>$ combination of micro dimple and $\mathrm{MoS}_{2}$ shot treatments.

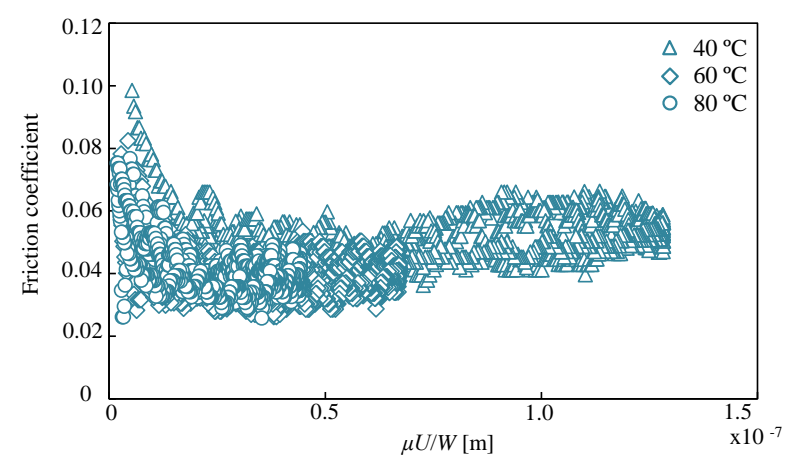

Fig. 7. Stribeck diagram in no treatment $(1000 \mathrm{rpm})$

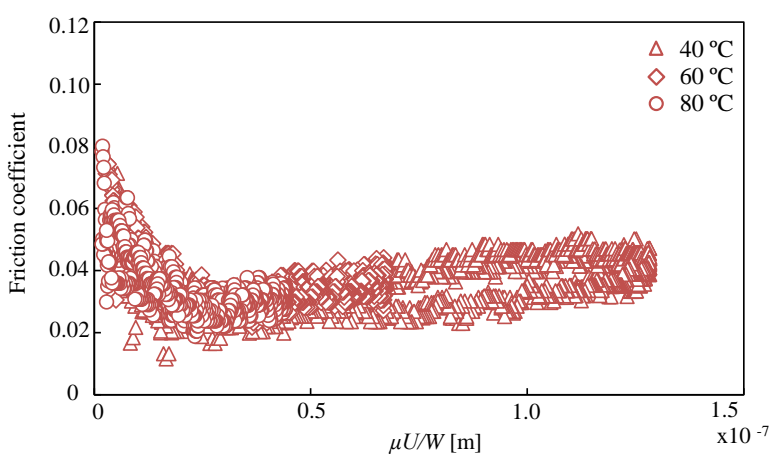

Fig. 8. Stribeck diagram in micro dimple treatment $(1000 \mathrm{rpm})$

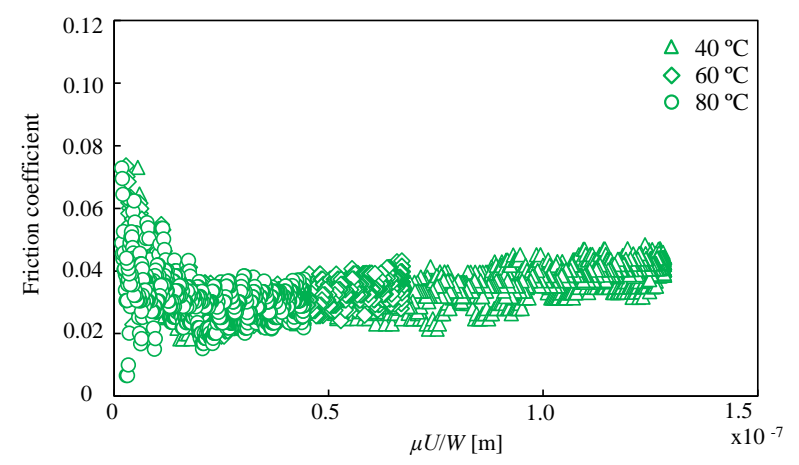

Fig. 9. Stribeck diagram in $\mathrm{MoS}_{2}$ shot treatment (1000 rpm) 


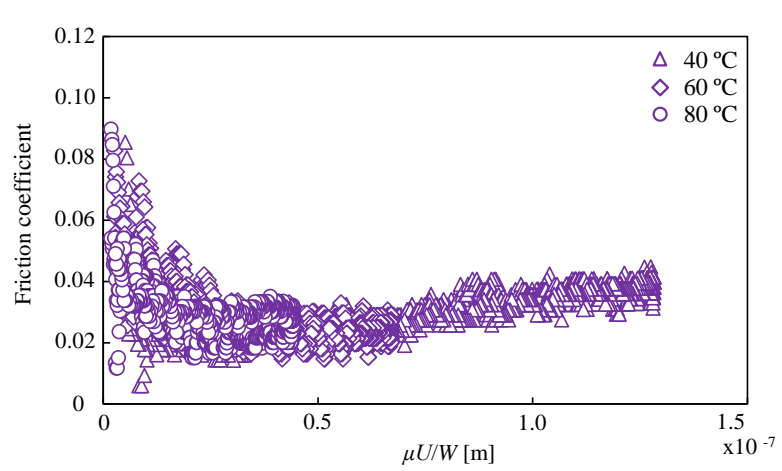

Fig. 10. Stribeck diagram in combination of micro dimple and $\mathrm{MoS}_{2}$ shot treatments $(1000 \mathrm{rpm})$

Figures 11 to 13 show the friction mean effective pressure (FMEP) at $40^{\circ} \mathrm{C}, 60^{\circ} \mathrm{C}$ and $80^{\circ} \mathrm{C}$, respectively. Here the FMEP was obtained by integrating the absolute value of friction at crank angles of $0^{\circ}$ to $360^{\circ}$ and dividing by the stroke volume. At each temperature and engine speed, the FMEP also tended to decrease in the following order: no treatment $>$ micro dimple treatment $>\mathrm{MoS}_{2}$ shot treatment $>$ combination of micro dimple and $\mathrm{MoS}_{2}$ shot treatments. At a lower temperature, as the engine speed increased, fluid lubrication became dominant, so the FMEP increased in each piston. At a higher temperature, when the engine speed increased from $800 \mathrm{rpm}$ to $1200 \mathrm{rpm}$, boundary contact decreased, and the FMEP decreased in each piston. But when the engine speed further increased from $1200 \mathrm{rpm}$ to $1600 \mathrm{rpm}$, fluid lubrication became dominant, and the FMEP tended to increase in each piston. Here, the FMEP was reduced by $31 \%$ to $45 \%$ for the combination of micro dimple and $\mathrm{MoS}_{2}$ shot treatments, compared to no treatment.

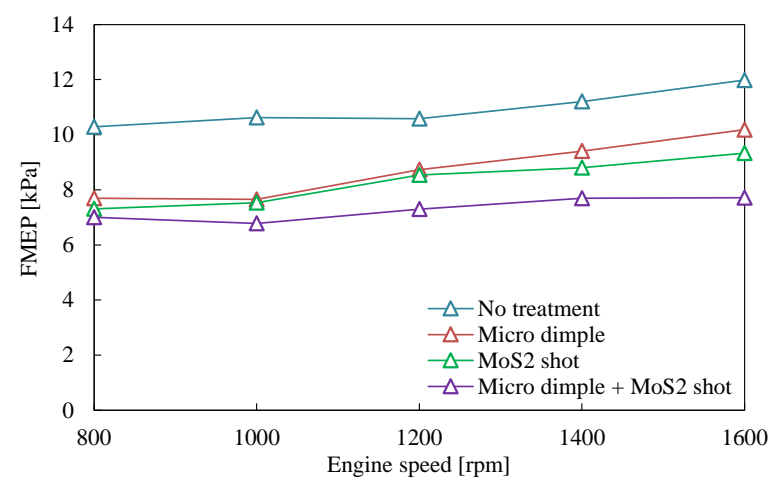

Fig. 11. FMEP at $40^{\circ} \mathrm{C}$

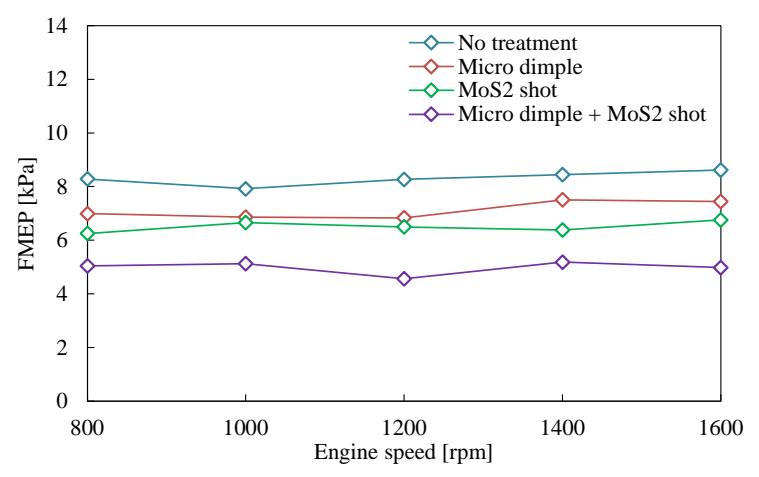

Fig. 12. FMEP at $60^{\circ} \mathrm{C}$

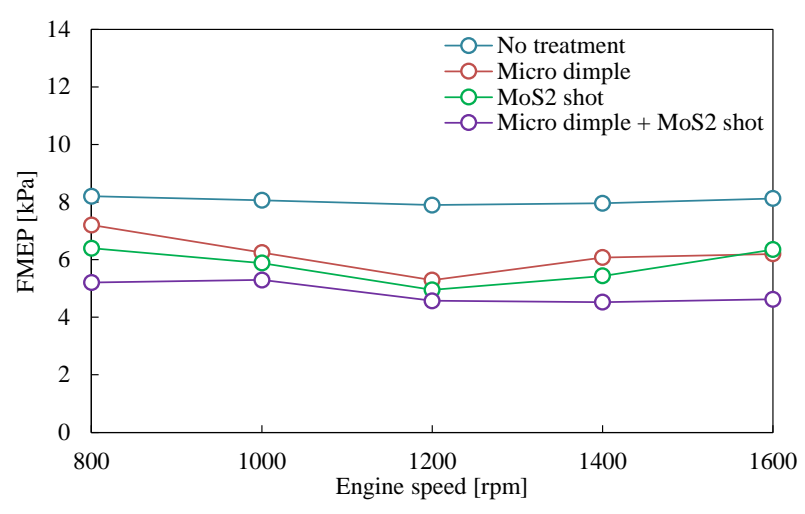

Fig. 13. FMEP at $80^{\circ} \mathrm{C}$

Figure 14 shows the maximum amount of wear on the streaked sliding surface at location " $\mathrm{C}$ " of each piston skirt after the friction measurement. All pistons had the maximum amount of wear on the streaked sliding surface at the piston skirt " $C$ " at both the thrust and the anti-thrust sides. In Fig. 14, except for the micro dimple treatment, there was no significant difference in the maximum amount of wear on each piston skirt. Except for the micro dimple treatment, the maximum amount of wear at the anti-thrust side was larger than that at the thrust side. At the thrust side, the maximum amount of wear with the micro dimple treatment was greater than that of all other treatments, including no treatment. It was considered that the outer diameter of the streaked surface became larger due to the micro dimple treatment. Figure 15 shows the observation results of the streaked surface at the piston skirt "C" on the anti-thrust side. In Fig. 15, the micro dimples remained even on the worn surface of the streak, with both the micro dimple treatment and the combination of the micro dimple and the $\mathrm{MoS}_{2}$ shot treatments. In all pistons, the amount of wear on the streaked sliding surface at locations (skirt "A," "B" and " $D$ ") other than skirt "C" was $0 \sim 1 \mu \mathrm{m}$, and there was no significant difference in the amount of wear.

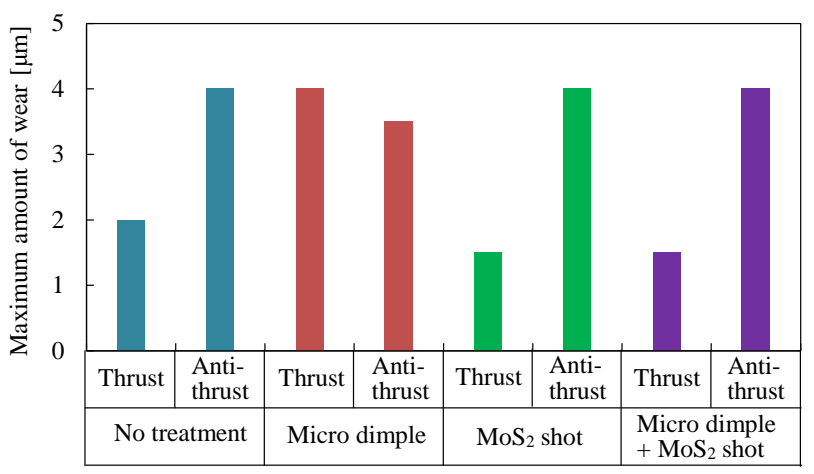

Fig. 14. Maximum amount of wear on streaked sliding surface at part of "C" after friction measurement

The micro dimple treatment reduced friction compared to no treatment. The micro dimples also remained on the worn surface of the streak with the micro dimple treatment. It is thought that, in the mixed lubrication region, the lubricant in the valley between streaks circulated through micro dimples as a passage, covering not only the actual sliding 
surfaces but also those micro dimples there, reducing friction [9]. It is also considered that, in the fluid lubrication region, the shear force of the lubricant between the sliding surfaces became smaller due to the formation of a vortex inside each micro dimple, reducing friction [12].

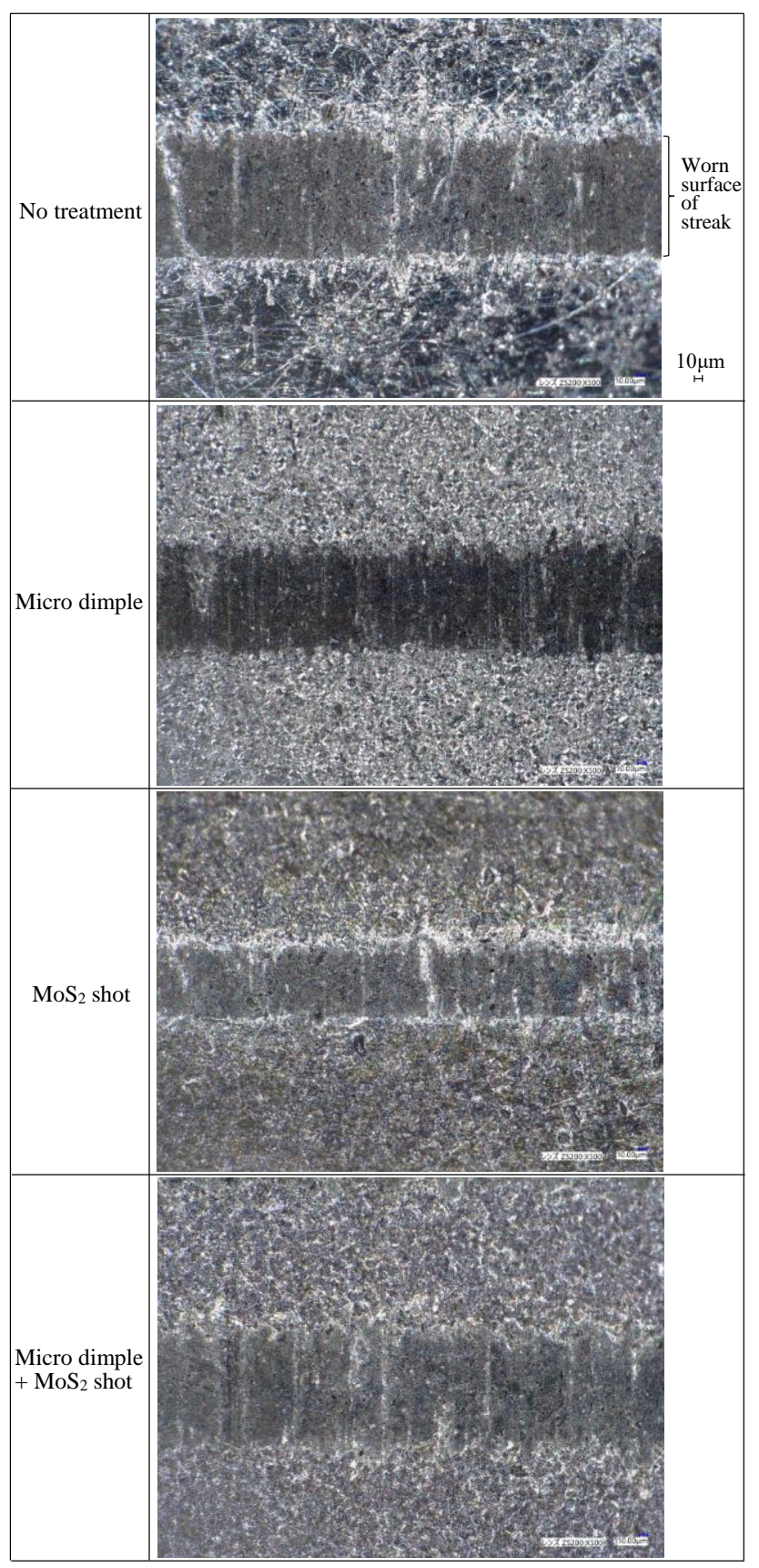

Fig. 15. Observation results of streaked surface at piston skirt " $\mathrm{C}$ " at antithrust side after friction measurement
The $\mathrm{MoS}_{2}$ shot treatment further reduced friction, more than both no treatment and the micro dimple treatment. The $\mathrm{MoS}_{2}$ has a hexagonal layered crystal structure, and in each layer a plane of molybdenum (Mo) atoms is sandwiched by planes of sulfur (S) atoms. The covalent bonds between the Mo and $\mathrm{S}$ atoms within layers are relatively strong, while the van der Waals forces cohering $S$ and $S$ atoms between layers are considerably weaker. Therefore the shear force acts between these layers, so interlayer sliding occurs, reducing friction. However, as shown in Fig. 14, the streaked surface at the piston skirt " $C$ " had a maximum wear of 4 $\mu \mathrm{m}$, which corresponded to approximately the depth of the treatment of $\mathrm{MoS}_{2}$ shots. Here, Ogihara [10,11] examined the worn part of the streaked $\mathrm{MoS}_{2}$ treated piston skirt, after engine motoring, using Field Emission Scanning Electron Microscopy/Energy Dispersive X-ray Spectroscopy (FE$\mathrm{SEM} / \mathrm{EDX}$ ), and confirmed the remaining presence of $\mathrm{MoS}_{2}$ both on the worn surface and deep inside the surface. This is because the $\mathrm{MoS}_{2}$ particles are repeatedly cleaved and transferred to other areas. As in Ogihara [10, 11], this study considered that the cleaved $\mathrm{MoS}_{2}$ particles were transferred to the worn surface. In the mixed lubrication region, the sliding force acted between $\mathrm{MoS}_{2}$ layers, facilitating interlayer sliding and reducing friction. It seems that, in the fluid lubrication region, the cleaved $\mathrm{MoS}_{2}$ particles decreased the shear force of the lubricant, reducing friction.

The combination of the micro dimple and the $\mathrm{MoS}_{2}$ shot treatments further reduced friction in all regions. It was thought that, in the mixed lubrication region, not only the $\mathrm{MoS}_{2}$ interlayer sliding occurred (by the sliding force acting between layers) but also lubricant was supplied to the sliding surface through micro dimples, further reducing friction. In the fluid lubrication region, the shear force of the lubricant between the sliding surfaces decreased, due to both the cleaved $\mathrm{MoS}_{2}$ particles and the vortices generated inside the micro dimples, further reducing friction.

\section{Conclusions}

Using a friction measurement apparatus with a floating cylinder liner, similar to an eco-mileage vehicle engine, the effect of piston surface treatment with the FPB process on piston assembly friction was investigated. Results indicated that, the micro dimple and the $\mathrm{MoS}_{2}$ shot treatments reduced friction. The $\mathrm{MoS}_{2}$ shot treatment reduced friction more than the micro dimple treatment. Finally, the combination of both the micro dimple and the $\mathrm{MoS}_{2}$ shot treatments further reduced friction. This combination of micro dimple and $\mathrm{MoS}_{2}$ shot treatments reduced friction from $31 \%$ to $45 \%$, compared to no treatment.

\section{Acknowledgements}

We would like to thank Fujikihan Co., Ltd. for treating the piston surfaces with the FPB process.

\section{Nomenclature}

BDC bottom dead center

FE-SEM/EDX Field Emission Scanning Electron Microscopy/Energy Dispersive X-ray Spectroscopy

FMEP friction mean effective pressure

FPB fine particle bombarding

Mo molybdenum
$\mathrm{MoS}_{2}$ molybdenum disulfide

$\mathrm{Ra} \quad$ calculated average roughness

$\mathrm{Rz}_{\mathrm{JIS}} \quad 10$-point average roughness

$S \quad$ sulfur

TDC top dead center 


\section{Bibliography}

[1] HOSHI, M. Reducing friction losses in automobile engines. Tribology International. 1984, 17(4), 185-189.

https://doi.org/10.1016/0301-679X(84)90017-3

[2] KANAI, S., TARESAWA, C., FUJIWARA, N. Friction reduction technology of the piston for gasoline engine. Transactions of the Society of Automotive Engineers of Japan. 2013, 44(2), 381-386.

https://doi.org/10.11351/jsaeronbun.44.381 (in Japanese).

[3] KOVACH, J., TSAKIRIS, E., WONG, L. Engine friction reduction for improved fuel economy. SAE Technical Paper 820085. 1982. https://doi.org/10.4271/820085

[4] MATSUMOTO, K. Friction reduction in an internal combustion engine. Journal of the Japan Society of Mechanical Engineers. 1976, 79(694), 870-876.

https://doi.org/10.1299/jsmemag.79.694_870 (in Japanese).

[5] MURAKAMI, M., KONOMI, T., NOHIRA, H. et al. Analysis of piston frictional force under engine firing condition. Effects of surface characteristics of piston skirt on friction. Transactions of the Society of Automotive Engineers of Japan. 1991, 22(4), 70-73. (in Japanese).

[6] NAKADA, M. Trends in engine technology and tribology. Tribology International. 1994, 27(1), 3-8. https://doi.org/10.1016/0301-679X(94)90056-6

[7] NAKANISHI, K., OKADA, Y., SERA, K. et al. Teardown analysis for piston assembly friction with optimization controls. Honda $R$ \& D Technical Review. 2010, 22(1), 154159.

[8] NAKASHIMA, K., UCHIYAMA, Y. Experimental development of apparatus to measure piston assembly friction in an eco-mileage vehicle engine. Combustion Engines. 2019, 177(2), 55-59. https://doi.org/10.19206/CE-2019-210

Prof. Kohei Nakashima, DEng. - Department of Vehicle and Mechanical Engineering, Meijo University, Japan.

e-mail:nakasima@meijo-u.ac.jp
[9] OGIHARA, H., KIDO, T., YAMADA, H. et al. Technology for reducing engine rubbing resistance by means of surface improvement. Honda $R \& D$ Technical Review. 2000, 12(2), 93-98.

[10] OGIHARA, H. Modification of piston sliding surface for internal combustion engine by fine particle peeing of solid lubricant. Tribologist. 2002, 47(12), 895-900. (in Japanese).

[11] OGIHARA, H. Research into surface improvement for low friction pistons. SAE Transactions Journal of Engines. 2005, 114(3), 1182-1190. https://doi.org/10.4271/2005-01-1647

[12] PODGORNICK, B., VILHENA, L., SEDLACEK, M. et al. Effective and design of surface texturing for different lubrication regimes. Meccanica. 2012, 47, 1613-1622. https://doi.org/10.1007/s11012-012-9540-7

[13] SASAKI, M., TAKAHASHI, N., SATO, T. et al. Development of low friction solid film lubricant for piston (First report) Development of double layer solid film lubricant, 2010 JSAE Annual Congress (Spring) Proceedings, 2010, 82(10), 7-10. (in Japanese).

[14] SUGIMURA, K. Development of piston treatment for internal combustion engine. SAE International Journal of Materials and Manufacturing. 2008, 1(1), 824-831. https://doi.org/10.4271/2008-01-1462

[15] TAKIGUCHI, M., TAKIMOTO, T., ASAKAWA, E. et al. A study of friction force reduction on piston skirt (Effect of width, roughness and resin coating). Transactions of the Japan Society of Mechanical Engineers B, 1997, 63(611), 2587-2592. https://doi.org/10.1299/kikaib.63.611_2587 (in Japanese).
Yosuke Uchiyama, MEng. - Department of Vehicle and Mechanical Engineering, Meijo University Graduate School, Japan.

e-mail:150446017@ccalumni.meijo-u.ac.jp 